\title{
Facile Synthesis of ZnO Flower-Like Micro/nanostructures with Enhanced Antibacterial Activity
}

\author{
Kok Ann Wong ${ }^{1}$, Sze Mun $\mathrm{Lam}^{1 *}$ and Jin Chung $\mathrm{Sin}^{2}$ \\ ${ }^{1}$ Department of Environmental Engineering, Faculty of Engineering and Green Technology, Universiti \\ Tunku Abdul Rahman, Jalan Universiti, Bandar Barat, 31900 Kampar, Perak, Malaysia \\ ${ }^{2}$ Department of Petrochemical Engineering, Faculty of Engineering and Green Technology, Universiti \\ Tunku Abdul Rahman, Jalan Universiti, Bandar Barat, 31900 Kampar, Perak, Malaysia
}

\begin{abstract}
Flower-like $\mathrm{ZnO}$ micro/nanostructures were synthesized via a simple reflux route without addition of surfactant. The characterization of as-synthesized $\mathrm{ZnO}$ sample was performed using $\mathrm{X}$-ray diffraction, fieldemission scanning electron microscopy and photoluminescence spectroscopy. The activity of the as-synthesized photocatalyst was evaluated using colony counting method under UV irradiation. The results showed that the as-synthesized $\mathrm{ZnO}$ sample exhibited excellent photocatalytic disinfection towards Escherichia coli. A possible disinfection mechanism was also postulated based on the findings from microscopic images and radical scavenging experiments.
\end{abstract}

\section{Introduction}

Clean water, which is free of pathogenic bacteria and harmful substances is necessary for the human being. In an aqueous environment, the waterborne pathogens including protozoa, fungi, bacteria, prions and viruses and the pathogen-related diseases have caused a considerable risk to public health [1,2]. Thus, it become an essential concern worldwide to secure safe water for the human being. The traditional treatment method that commonly applied is through chemical disinfection. The chemicals such as chlorine and ozone are mostly used for the removal of organic pollutants. Nevertheless, this treatment method often leads to the generation of harmful by-products $[3,4]$.

Recently, the development of light-induced catalytic and antibacterial materials that able to mineralize organic pollutants and inactivate microorganisms has drawn significant attention [4,5]. Irradiation of photocatalyst with light energy results in the formation of reactive oxygen species (ROS), which lead to mineralization of organic pollutants and bacterial inactivation. Among the photocatalysts, zinc oxide $(\mathrm{ZnO})$ has been widely studied because of its large band gap energy $(\sim 3.4 \mathrm{eV})$, large exciton binding energy $(\sim 60 \mathrm{meV})$ and widely applied in solar cells, gas sensors and photocatalysts [6,7]. It is well known that nanostructured photocatalysts can exhibit better properties due to its smaller size, which are

${ }^{*}$ Corresponding author: $\underline{\text { lamsm } @ \text { utar.edu.my }}$ 
significantly different from those of their bulk counterparts [1]. Until now, various methods such as hydrothermal, electrochemical deposition and sol-gel method have been utilized to produce $\mathrm{ZnO}$ nanostructures. The reflux method is more advantageous than other methods in the context of simple, economical, low operating temperature and high yield without the use of any expensive equipment [8]. Moreover, this method can produce nanomaterials with well-defined size and shape without addition of any surfactant or templates $[8,9]$.

In this study, flower-like $\mathrm{ZnO}$ micro/nanostructures has been assembled via a simple, productive and surfactant-free reflux route. The characterization of as-synthesized $\mathrm{ZnO}$ were then performed by field emission-scanning electron microscopy (FESEM), X-ray diffraction (XRD) and photoluminescence (PL) spectroscopy. The antibacterial activity of assynthesized $\mathrm{ZnO}$ was evaluated against Escherichia coli $(E$. coli) under UV illumination. Furthermore, radical scavenging experiment was conducted to determine the main active species that involved in the $E$. coli inactivation. A possible mechanism for the antibacterial activity against $E$. coli over as-synthesized $\mathrm{ZnO}$ was also explained.

\section{Experimental}

In this research, all of the chemicals were in analytical grade and used as-purchased were not further purification. All solutions were prepared with deionized water in this study.

\subsection{Construction of flower-like $\mathrm{ZnO}$ micro/nanostructures}

$\mathrm{Zn}\left(\mathrm{NO}_{3}\right)_{2} \cdot 6 \mathrm{H}_{2} \mathrm{O}(0.1 \mathrm{M})$ was first dissolved in $100 \mathrm{~mL}$ DI. Then, the solution was added with $100 \mathrm{~mL}$ of $\mathrm{NaOH}(0.1 \mathrm{M})$ under continuous stirring. Mixture solution $\mathrm{pH}$ value was tuned to 12 using extra $\mathrm{NaOH}$ and refluxed at $65^{\circ} \mathrm{C}$ for $8 \mathrm{~h}$. After the solution was cooled down, the precipitates were washed, filtered, dried at $80^{\circ} \mathrm{C}$ and calcined at $550^{\circ} \mathrm{C}$.

\subsection{Characterization}

The as-synthesized $\mathrm{ZnO}$ were investigated by XRD using Philips PW1820 diffractometer with $\mathrm{Cu} \mathrm{K} \alpha$ radiation at scanning rate of $2^{\circ} \mathrm{min}^{-1}$ in the range of $20^{\circ}-80^{\circ}$. The morphology of the $\mathrm{ZnO}$ was analyzed by FESEM JEOL 6701-F. The PL spectroscopy was performed by a Perkin Elmer Lambda S55 spectrofluorometer using a Xe lamp with an excitation wavelength of $325 \mathrm{~nm}$ under room temperature.

\subsection{Antibacterial activity test}

The antibacterial activity test was conducted using colony counting methods. E. coli was chosen as the target bacteria. The $E$. coli were cultivated in nutrient broth medium at $37^{\circ} \mathrm{C}$. Then, the optical densities of the bacteria were measured at $600 \mathrm{~nm}$ using a DR-6000 UVVis spectrophotometer. For the photocatalytic inactivation experiment, diluted E. coli suspension $\left(10^{5} \mathrm{CFU} / \mathrm{mL}\right)$ was mixed with $400 \mathrm{~mL}$ of sterile saline water in a Pyrex reactor. To optimized the bacteria growth, the temperature was set to $37^{\circ} \mathrm{C} .1 \mathrm{~g} / \mathrm{L}$ of photocatalyst was then added and continuously stirred for $30 \mathrm{~min}$ without light to reach adsorption equilibrium. A Pen-ray UV-C was utilized as a light source for the experiment. At certain time point of UV irradiation, $1 \mathrm{~mL}$ of sample was withdrawn out and filtered to remove the suspended solids. Subsequently, the sample was diluted and spread on nutrient agar plates. The colonies on nutrient agar plates were observed after incubated for $24 \mathrm{~h}$ at $37^{\circ} \mathrm{C}$. 


\subsection{Detection of reactive oxygen species (ROS)}

In order to detect ROS role in photocatalytic inactivation experiment, hydroxyl radicals $(\bullet \mathrm{OH})$, holes $\left(\mathrm{h}^{+}\right)$and superoxide anion $\left(\mathrm{O}_{2}{ }^{-*}\right)$ were scavenged by adding $2 \mathrm{mM}$ of isopropanol (IPA), ethylenediaminetetraacetic acid disodium salt (EDTA-2Na) and p-benzoquinone (BQ), respectively. The procedures of radical scavenging test were similar to the antibacterial activity test above.

\section{Results and discussion}

Fig. 1 presents the FESEM images of the as-synthesized ZnO. As shown in Fig. 1a, the production of $\mathrm{ZnO}$ sample was in high yield. It showed that the presence of flower-like structures with varied average size from $800 \mathrm{~nm}$ to $2.6 \mu \mathrm{m}$. Higher magnification FESEM image in Fig. 1b displayed the flower-like $\mathrm{ZnO}$ micro/nanostructures with some petals like protrusion coming out to different direction from the center.
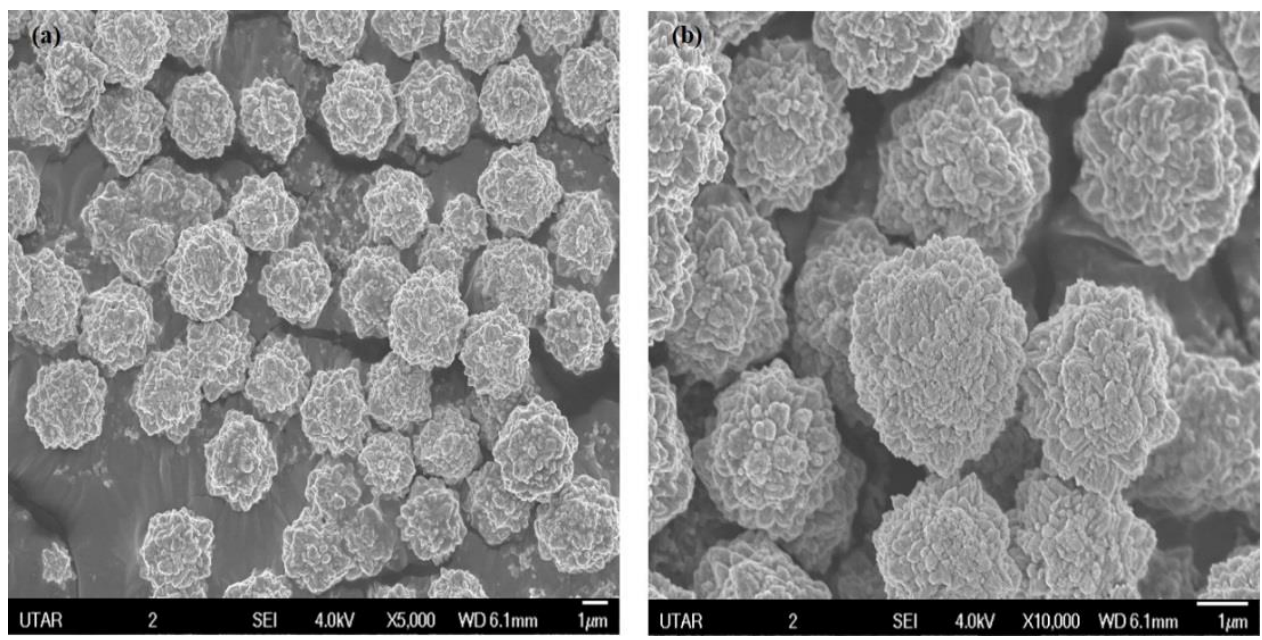

Fig. 1. FESEM images of as-synthesized magnified at different magnifications (a) 5,000x and (b) $10,000 x$.

Based on FESEM images, a simple growth mechanism for as-synthesized $\mathrm{ZnO}$ was proposed. At initial stage, the $\mathrm{Zn}(\mathrm{OH})_{2}$ was formed when $\mathrm{Zn}^{2+}$ cation reacts with $\mathrm{OH}^{-}$anions. The interior of $\mathrm{Zn}(\mathrm{OH})_{2}$ was then started to dehydrate and formed large amount of $\mathrm{ZnO}$ nuclei. These $\mathrm{ZnO}$ nuclei would tend to aggregate together to minimize their surface area under the surface energy driving forces through Ostwald ripening [10]. Subsequently, these aggregates could grow anisotropically along its c-axis and self-assembly into $\mathrm{ZnO}$ flower-like micro/nanostructures. Thus, flower-like $\mathrm{ZnO}$ micro/nanostructures was successfully assembled via an uncomplicated, low cost and surfactant-free route.

Fig. 2 shows the XRD analysis of the as-synthesized $\mathrm{ZnO}$. The diffraction peaks in XRD result were characterized and well-coordinated with $\mathrm{ZnO}$ hexagonal wurtzite structure (JCPDS No. 36-1451) [6,7]. The sharp and narrow peaks implied that the as-synthesized $\mathrm{ZnO}$ sample were highly crystalline. In addition, no impurity peaks were detected in the sample, indicating high purity of sample. 


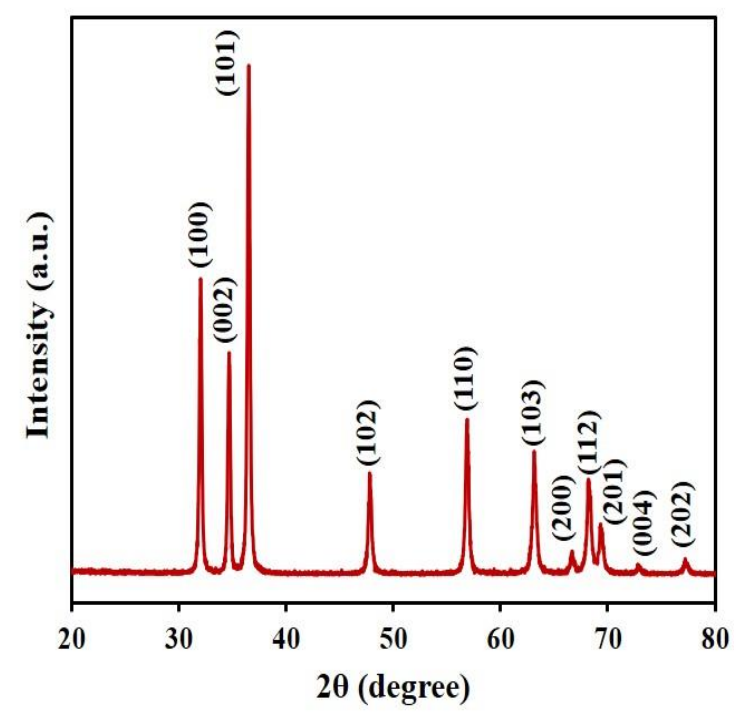

Fig. 2. XRD pattern of $\mathrm{ZnO}$ flower-like micro/nanostructures.

The PL test was conducted for the $\mathrm{ZnO}$ flower-like micro/nanostructures. As shown in Fig. 3, the emission peaks centered at $423 \mathrm{~nm}, 463 \mathrm{~nm}, 490 \mathrm{~nm}$ and $533 \mathrm{~nm}$ were observed. The violet $(423 \mathrm{~nm})$ and blue emission $(463 \mathrm{~nm})$ were attributed to the defect luminescence or deep level emission from the oxygen vacancies [11,12]. For the green emissions $(490 \mathrm{~nm}$ and $533 \mathrm{~nm}$ ), it was due to the oxygen vacancies or deep interstitial oxygen [13]. The result suggested that the $\mathrm{ZnO}$ flower-like micro/nanostructures have some oxygen vacancies or deep interstitial oxygen. The oxygen vacancies acted as electron acceptors and temporarily trapped the photogenerated electron ( $\left.\mathrm{e}^{-}\right)$to decrease the $\mathrm{e}^{-}-\mathrm{h}^{+}$pair recombination, whereas the deep interstitial oxygen served as trappers for photogenerated $\mathrm{h}^{+}$to restrain the recombination of $\mathrm{e}^{-}-\mathrm{h}^{+}$pair, which improve the photocatalytic performance of photocatalyst $[14,15]$.

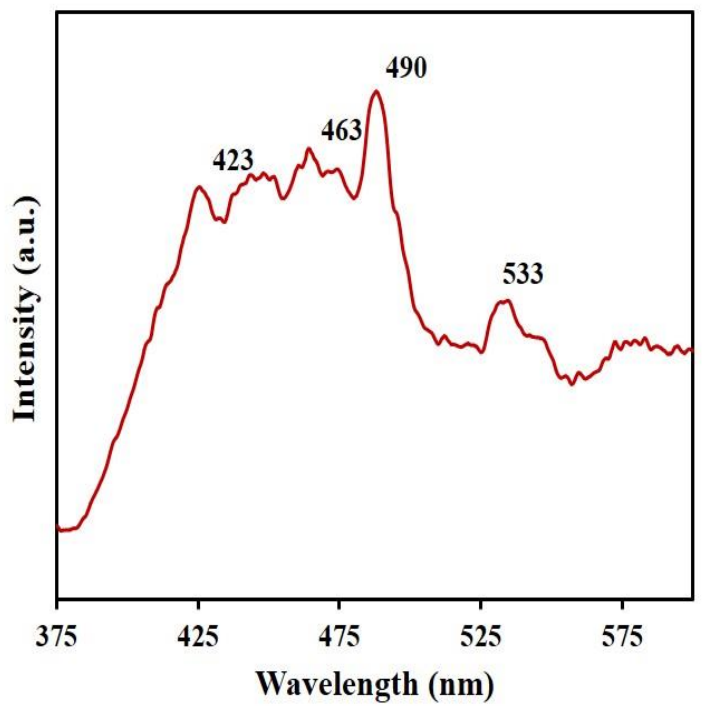

Fig. 3. PL spectrum of $\mathrm{ZnO}$ flower-like micro/nanostructures at room temperature. 
The antibacterial properties of as-synthesized $\mathrm{ZnO}$ was evaluated by colony counting method under UV irradiation and the results are presented in Fig. 4. E. coli was selected as that target bacteria in this study. E. coli can lead to life threatening blood stream infection that related with urinary, gastrointestinal or central nervous systems diseases in human [16]. Control experiments such as photolysis and dark run were conducted prior to the experiment. The results showed that the number of bacteria only decreased slightly under photolysis and dark run. However, under UV irradiation, the $\mathrm{ZnO}$ flower-like micro/nanostructures exhibited excellent antibacterial performance towards $E$. coli. Such good performance can be associated to the morphology and oxygen vacancies of $\mathrm{ZnO}$ micro/nanostructures. The petal of flower-like structure could penetrate the cell walls of bacteria easily and lead to cell death. Then, the oxygen vacancies could greatly improve the $\mathrm{e}^{-}-\mathrm{h}^{+}$pair separation which enhanced the photocatalytic performance. Furthermore, the ROS generated could be another reason that terminating the bacterial cells as the ROS could damage the cell membrane and release cellular constituents including lipids and proteins $[5,16]$.

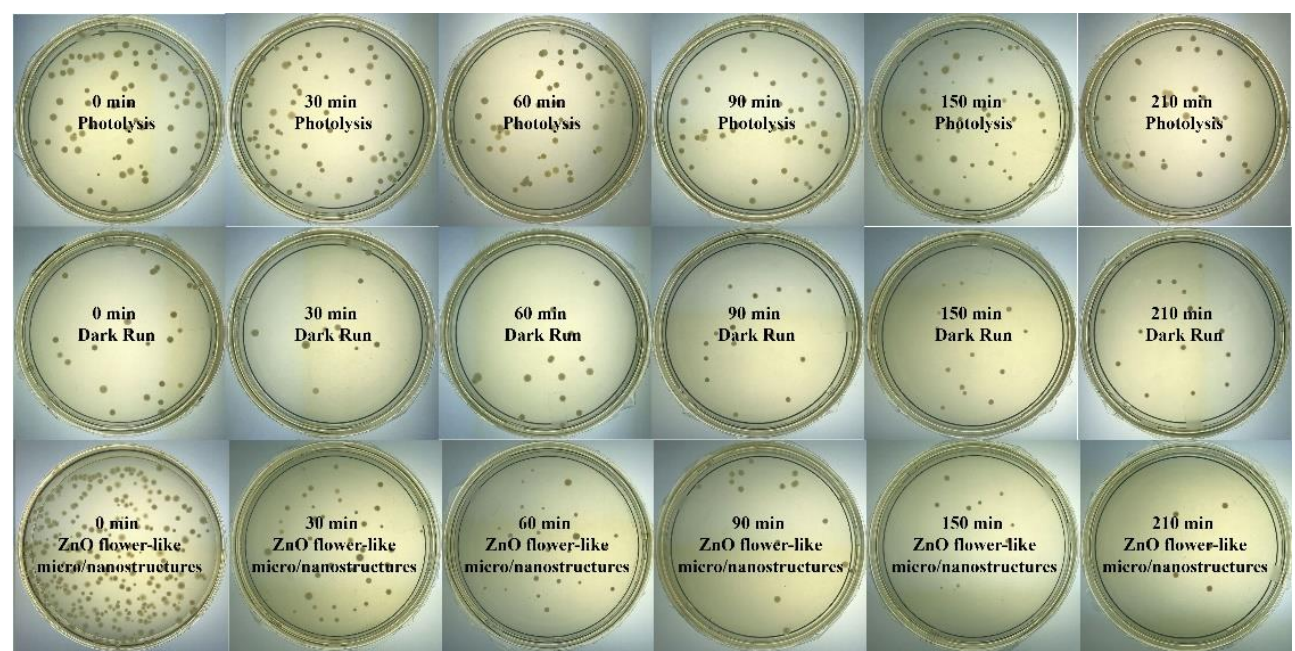

Fig. 4. Photolysis, dark run and photocatalytic antibacterial activity of $\mathrm{ZnO}$ flower-like micro/nanostructures towards E. coli under UV illumination.

To further interpret photocatalytic disinfection process, radical scavenging tests were conducted to evaluate the main ROS that partook in the photocatalytic disinfection process. From Fig. 5, the antibacterial activity of $\mathrm{ZnO}$ flower-like micro/nanostructures only decreased slightly when BQ was added. By adding EDTA-2Na, a noticeably suppression of E. coli was observed within $210 \mathrm{~min}$ UV irradiation. On the contrary, the antibacterial activity was decreased significantly with the addition of IPA. Thus, these results confirmed that $\bullet \mathrm{OH}$ were the main ROS that responsible for the antibacterial activity towards E. coli. 


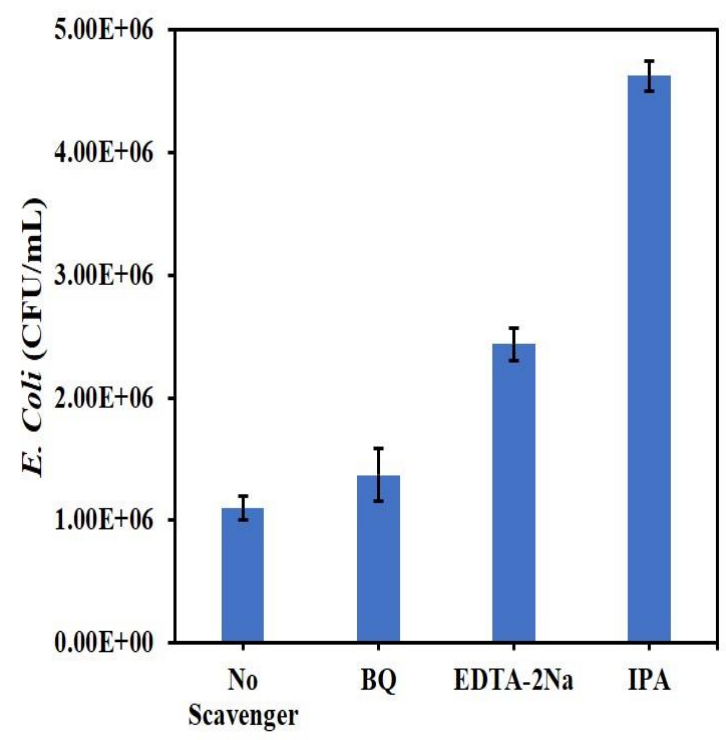

Fig. 5. Radical scavenging tests on disinfection properties of as-synthesized $\mathrm{ZnO}$ towards $E$. coli under UV illumination.

The morphological changes of $E$. coli before and after the photocatalytic inactivation experiment was observed using FESEM analysis to verify the destruction of E. coli cells photocatalyzed by $\mathrm{ZnO}$ flower-like micro/nanostructures. From Fig. 5a, well-preserved rod like structure was observed in the untreated $E$. coli cells. On the other hand, the treated $E$. coli cells in Fig. 5b displayed the cells were severely deformed and ruptured, indicating the damage of cell membrane and leakage of cytoplasm. This result further confirmed the antibacterial activity of $\mathrm{ZnO}$ flower-like micro/nanostructures toward E. coli under UV irradiation.
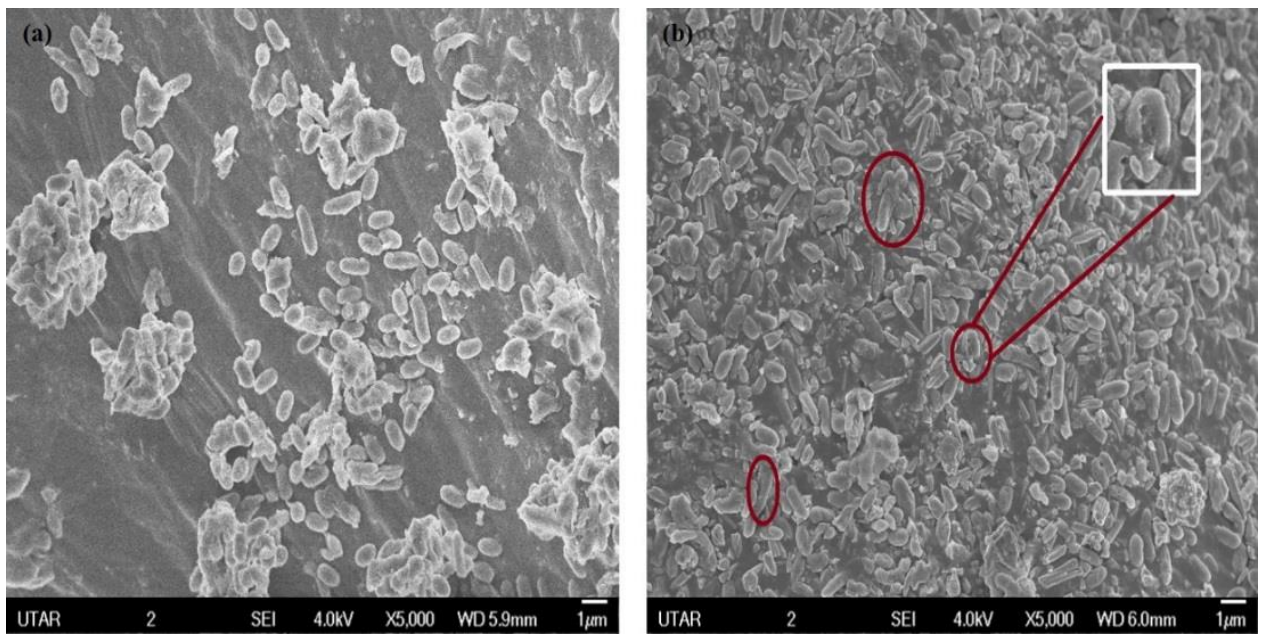

Fig. 6. FESEM images of E. coli (a) untreated and (b) photocatalyzed by as-synthesized ZnO.

According to the experimental results, a possible mechanism was postulated for the antibacterial properties of as-synthesized $\mathrm{ZnO}$ and presented in Fig. 7. Upon UV irradiation on as-synthesized $\mathrm{ZnO}$, photogenerated $\mathrm{e}^{-}$was moved from valence band (VB) to conduction 
band (CB), leaving $\mathrm{h}^{+}$in VB. Photogenerated $\mathrm{e}^{-}-\mathrm{h}^{+}$pair was then undergone reduction and oxidation to generate ROS including $\bullet \mathrm{OH}, \mathrm{O}_{2}{ }^{--}$and $\mathrm{h}^{+}$. The $\bullet \mathrm{OH}$ and $\mathrm{O}_{2}{ }^{--}$were the main species the responsible for the photocatalytic disinfection process in this study. Subsequently, these ROS would attack the bacteria cells by degrading the cell membrane and lead to leakage of biomolecules such as carbohydrate, lipids, DNA, nucleic acid and proteins and finally kill the bacteria cell as validated in the FESEM analysis from Fig. 6. Hence, the $\mathrm{ZnO}$ flower-like micro/nanostructures was a promising material in photocatalytic disinfection of bacteria.
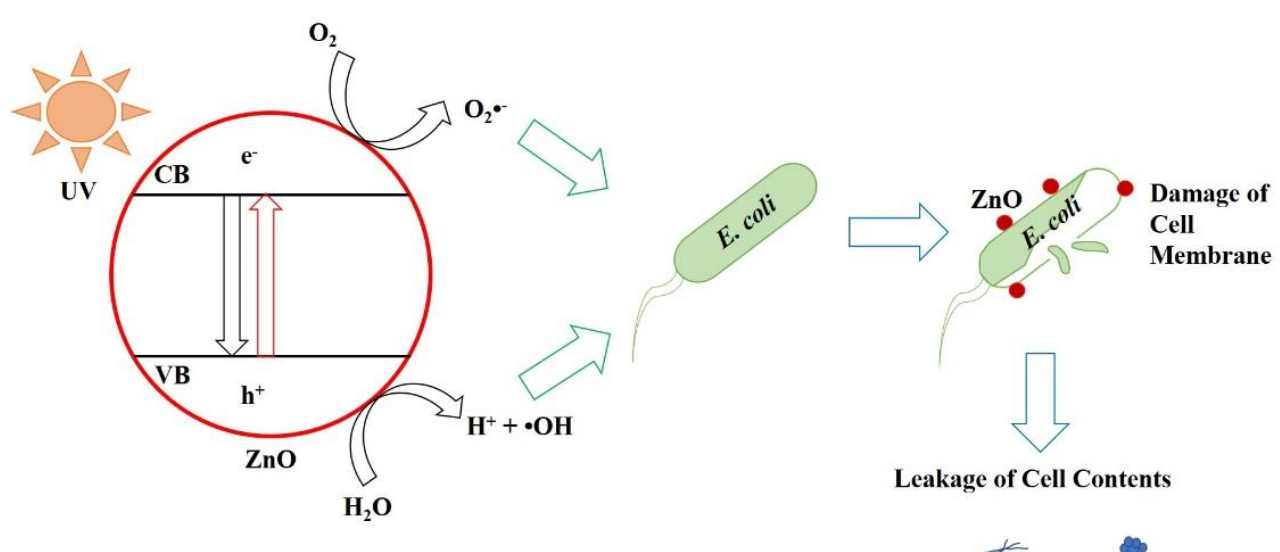

Fig. 7. Schematic diagram of antibacterial mechanism of as-synthesized $\mathrm{ZnO}$.

\section{Conclusions}

In this study, flower-like $\mathrm{ZnO}$ micro/nanostructures was successfully assembled via an uncomplicated and surfactant-free reflux route. Several analyses including FESEM, XRD and PL were employed to determine the optical and physico-chemical properties of assynthesized $\mathrm{ZnO}$ flower-like micro/nanostructures. The $\mathrm{ZnO}$ flower-like micro/nanostructures exhibited excellent antibacterial activity towards E. coli under UV irradiation. The radical scavenging tests displayed that $\bullet \mathrm{OH}$ were the main ROS that partook in the antibacterial activity towards $E$. coli. Furthermore, the observation of $E$. coli destruction by FESEM further confirmed that the $E$. coli cell membranes were deformed after photocatalyzed by $\mathrm{ZnO}$ flower-like micro/nanostructures.

This work was supported by the Universiti Tunku Abdul Rahman (UTARRF/2016-C2/S03 and UTARRF/2017-C1/L02) and Ministry of Higher Education of Malaysia (FRGS/1/2015/TK02/UTAR/02/2 and FGRS/1/2016/TK02/UTAR/02/1).

\section{References}

1. M. R. Bindhu, M. Umadevi, M. K. Micheal, M. V. Arasu, N. A. Al-Dhabi, Mater. Lett., 166, 19 (2016).

2. M. Y. Song, H. D. Jung, J. Jurng, B. C. Kim, Appl. Catal. B: Environ., 148, 568 (2014).

3. J. Yin, Y. Niu, B. Shao, J. Environ. Sci., 55, 100 (2017).

4. Y. Zhang, Y. Shao, N. Gao, Y. Gao, W. Chu, S. Li, Y. Wang, S. Xu, Chem. Eng. J., 333, 85 (2018).

5. Y. Seo, B. E. Yeo, Y. S. Cho, H. Park, C. Kwon, Y. D. Huh, Mater. Lett., 197, 146 (2017). 
6. W. Guo, J. Mater. Sci: Mater. Electron., 27, 7302 (2016).

7. D. H. Jin, D. Kim, Y. Seo, H. Park, Y. D. Huh, Mater. Lett., 115, 205 (2014).

8. A.N. Kadam, T. G. Kim, D. S. Shin, K. M. Garadkar, J. Park, J. Alloys Compd., 710, 102 (2017).

9. K. Mageshwari, R. Sathyamoorthy, J. Park, Powder Technol., 278, 150 (2015).

10. J. Xie, P. Li, Y. Li, Y. Wang, Y. Wei, Mater. Chem. Phys., 114, 943 (2009).

11. F. Wang, X. Qin, D. Zhu, Y. Meng, L. Yang, Y. Ming, Mater. Lett., 117, 131 (2014).

12. B. J. Kwon, J. Y. Kim, S. M. Choi, S. J. An, 2014, Nanotechnology, 25, 1 (2014).

13. R. K. Biroju, P. K. Giri, S. Dhara, K. Imakita, M. Fujii, ACS Appl. Mater. Interfaces, 6, 377 (2013).

14. J. Wang, P. Liu, X. Fu, Z. Li, W. Han, X. Wang, Langmuir, 25, 1218 (2009).

15. X. Sun, J. Wu, Q. Li, Q. Liu, Y. Qi, L. You, Z. Ji, P. He, P. Sheng, J. Ren, W. Zhang, J. Lu, J. Zhang, Appl. Catal. B: Environ., 218, 80 (2017).

16. S. K. Ray, D. Dhakal, R. P. Pandey, S. W. Lee, Mater. Sci. Eng., C, 78, 1164 (2017). 